\title{
Failure of thrombolysis: experience with a policy of early angiography and rescue angioplasty for electrocardiographic evidence of failed thrombolysis
}

\author{
A G C Sutton, P G Campbell, E D Grech, D J A Price, A Davies, J A Hall, M J Stewart, \\ $M$ A de Belder
}

\begin{abstract}
Objective-To assess the outcome of a policy of emergency coronary angiography with or without rescue angioplasty in patients with acute myocardial infarction and ECG evidence of failed reperfusion after thrombolysis.

Design-A cohort study.

Setting-Regional cardiothoracic unit.

Patients-197 patients with acute myocardial infarction fulfilling a simple ECG criterion of failed reperfusion.

Interventions-Emergency coronary angiography proceeding to rescue angioplasty for inadequate antegrade flow.

Main outcome measures-Hospital mortality for all 197 patients; incidence of successful and failed rescue angioplasty; need for additional revascularisation in those receiving rescue angioplasty compared with those not treated in this way.

Results-197 patients had emergency angiography for ECG evidence of failed reperfusion; 156 patients received immediate rescue angioplasty. Overall hospital mortality for those undergoing rescue angioplasty was $11.5 \%$. Rescue angioplasty achieved TIMI 2 (11) or TIMI 3 (124) in 135 patients, who had a hospital mortality of $5.9 \%$. Failure to achieve at least TIMI 2 flow following rescue angioplasty occurred in 21 patients, with a hospital mortality of $48 \%$. In the 41 patients in whom immediate rescue angioplasty was not performed, reinfarction or requirement for revascularisation occurred in 37\%. Reinfarction occurred in three patients $(1.9 \%)$ who had immediate rescue angioplasty. Hospital mortality for the whole cohort was $10.7 \%$.

Conclusions-A policy of emergency coronary angiography proceeding to rescue angioplasty where appropriate reduces mortality in a high risk group to a level less than expected for patients with acute myocardial infarction and ECG evidence of failed reperfusion. Unsuccessful rescue angioplasty is associated with a high mortality.
\end{abstract}

(Heart 2000;84:197-204)

Keywords: acute myocardial infarction; rescue angioplasty; failed reperfusion

Current thrombolytic agents reduce the mortality of acute myocardial infarction but have significant limitations. The GUSTO-1 (global utilisation of streptokinase and tissue plasminogen activator for occluded coronary arteries) angiographic substudy showed a 90 minute arterial patency rate, defined by the presence of TIMI (thrombolysis in myocardial infarction trial) grade 2 or 3 flow, in only $54 \%$ of patients who received the standard dose of streptokinase and subcutaneous heparin. ${ }^{12}$ Only 29\% achieved the more beneficial TIMI 3 flow. Although superior, accelerated tissue plasminogen activator produced TIMI 3 flow at $90 \mathrm{~min}-$ utes in only $54 \%$ of patients. TIMI grade 3 flow is associated with a significantly lower 30 day mortality than TIMI grade 2 flow. ${ }^{3}$ Other angiographic studies ${ }^{4}$ have shown that flow in the infarct related vessel must be normal following thrombolysis in order to reduce mortality, and a meta-analysis has found no mortality advantage for the presence of TIMI 2 flow in comparison with TIMI 1 or TIMI 0 flow. ${ }^{6}$

Persistent ST segment elevation following thrombolytic treatment may be used as a noninvasive marker of persistent arterial occlusion, and as a marker it is associated with a poor prognosis. $^{78}$ However, data on the further management of patients in whom lytic treatment is unsuccessful are lacking. This is in part due to the difficulty of making the diagnosis of failed thrombolysis without recourse to invasive techniques. Rescue angioplasty is one option available in the further management of these patients, but the only randomised data on this technique come from one relatively small study performed before the modern coronary angioplasty era. ${ }^{9}$ That trial showed a reduction in the incidence of death or severe heart failure in the rescue angioplasty group in comparison with a group treated conservatively. Despite this, many units have no structured policy for the management of failed thrombolysis. ${ }^{10} 11$

Our policy is to perform coronary angiography when ECG criteria suggest persistent arterial occlusion, proceeding to rescue angioplasty of the infarct related vessel for inadequate antegrade flow. The aims of this prospective study were to determine the uptake of rescue angioplasty and the outcome of patients considered for this treatment.

\section{Methods}

INTRODUCTION OF A RESCUE ANGIOPLASTY SERVICE In 1995, a policy for the use of rescue angioplasty was set and incorporated into our 
coronary care unit guidelines. For our local coronary care unit, patients were admitted under the care of a general physician and referred to a cardiologist for consideration of rescue angioplasty for failed reperfusion. This treatment was offered to patients in whom failure to respond to thrombolytic treatment was identified using ECG criteria. In our unit, failed thrombolysis was diagnosed when, at two hours after the onset of thrombolytic treatment and in the absence of an accelerated idioventricular rhythm, there was failure of ST segment elevation to fall by $50 \%$ in the lead with maximum ST segment elevation before thrombolytic treatment was begun. However, anticipating some inevitable delays, we did not deny treatment for those patients in whom the post-thrombolysis ECG showing failure to reperfuse was performed more than two hours after the onset of lytic treatment.

The same treatment was offered to patients from surrounding district general hospitals. Referring district general hospitals requested consideration for rescue angioplasty, based upon their own criteria for failed thrombolysis.

While our aim for all patients was to attempt percutaneous revascularisation within 12 hours of the onset of symptoms, we considered rescue angioplasty after this time for patients with persistent pain. Old age was not a contraindication to the procedure.

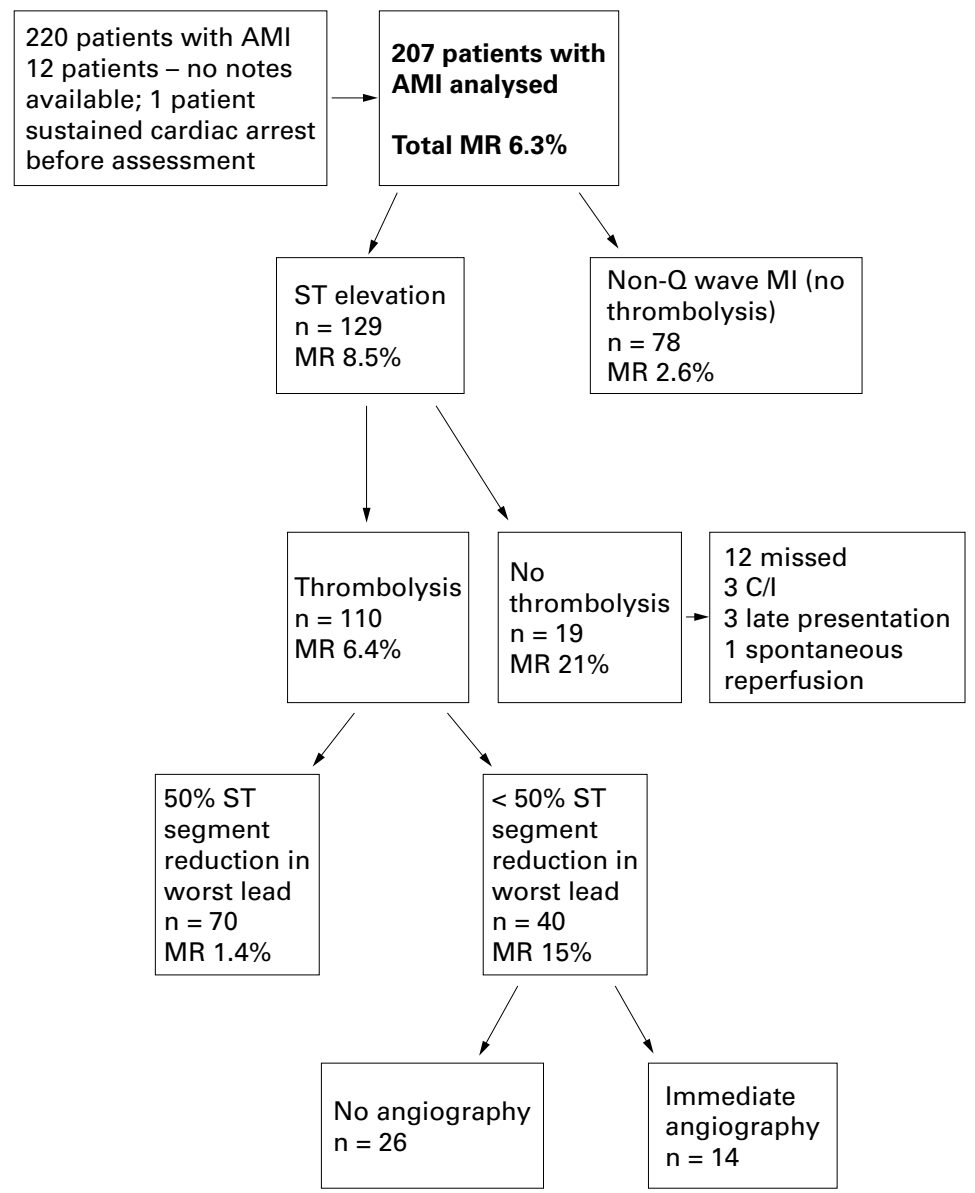

Figure 1 Patients with acute myocardial infarction (AMI) admitted to the coronary care unit in 1996. MR, hospital mortality.
DETERMINATION OF HIGH RISK WITH EARLY FAILURE TO REPERFUSE

A retrospective analysis of all patients presenting to our coronary care unit with acute myocardial infarction in 1996 was performed. The biochemistry results of all sequential patients admitted directly to the coronary care unit were reviewed. Patients transferred from surrounding district general hospitals were not analysed. The notes of any patient with a creatine kinase concentration more than twice the upper limit of normal for our laboratory were then requested. The diagnosis and ECG records of each patient were reviewed. In patients with acute myocardial infarction confirmed on the basis of ST segment elevation on the admitting ECG and a serial elevation in the cardiac enzymes, but without cardiogenic shock at presentation, the degree of ST segment reduction in the lead with maximum initial ST segment elevation was measured. The further management of such patients was recorded. Finally, the hospital mortality for the whole cohort was calculated.

ANGIOGRAPHIC SUBSTUDY TO ASSESS ECG CRITERIA FOR FAILED REPERFUSION

In August 1997, we performed an angiographic substudy to calculate the sensitivity, specificity, and positive and negative predictive values of various ECG criteria for the detection of inadequate antegrade flow in the infarct related vessel. ${ }^{12}$ A consecutive series of 100 patients was enrolled into this study and underwent coronary angiography two hours after the onset of thrombolytic treatment for acute myocardial infarction with ST segment elevation on the initial ECG. Rescue angioplasty was performed if the infarct related vessel was occluded. The study showed that, in the absence of accelerated idioventricular rhythm, the best ECG criterion for detecting failed reperfusion was failure of the ST segment elevation to fall by $50 \%$ two hours after treatment had been initiated, in the lead with maximum elevation on the prethrombolytic ECG. The patients fulfilling this ECG criterion of failed reperfusion are included in the analyses of the present study.

ANALYSIS OF ALL PATIENTS WITH ECG EVIDENCE OF FAILED REPERFUSION

In all, 156 patients received rescue angioplasty for failed reperfusion. In a further 41 patients, the ECG criterion of suspected failed reperfusion was present but immediate rescue angioplasty was not undertaken. Of the entire cohort of 197 patients, 86 were admitted directly to our coronary care unit and 111 were transferred from surrounding units directly to our cardiac catheterisation laboratory. The times between onset of chest pain and thrombolysis, and between thrombolysis and arrival in the cardiac catheterisation laboratory at South Cleveland Hospital, were recorded for all patients except for a few in whom the time of onset of major symptoms was unclear.

Coronary angiography was performed from the femoral artery in all patients. All patients received aspirin, if not allergic, and intravenous heparin according to protocol. Standard guide catheters and guidewires were used for all 
197 patients with rescue angioplasty or urgent coronary angiography for suspected failed reperfusion In hospital death $\mathrm{n}=21$ MR $10.7 \%$

Angiography for failed
reperfusion (no rescue
angioplasty)
$\mathrm{n}=41$
In hospital death $\mathrm{n}=3$
MR $7.3 \%$

\begin{tabular}{|l|l|}
\hline Rescue PTCA & Rescue PTCA \\
Final flow TIMI 2/3 & Final flow TIMI $<2$ \\
$\mathrm{n}=135$ & $\mathrm{n}=21$ \\
In hospital death $\mathrm{n}=8$ & In hospital death $\mathrm{n}=10$ \\
MR 5.9\% & MR 48\% \\
\hline
\end{tabular}

Figure 2 Patients undergoing a strategy of angiography with or without rescue angioplasty.

patients. In those in whom rescue angioplasty was performed, the decision to proceed to coronary artery stenting following initial balloon inflation was left to the discretion of the attending cardiologist, as was the use of further adjunctive treatment with intra-aortic balloon counterpulsation or glycoprotein IIb/IIIa inhibitors. Intra-aortic balloon pumps were used predominantly for abnormal antegrade flow following intervention, systemic hypotension, or left ventricular failure, or combinations of these. TIMI flow at the start and end of the procedure was recorded for each patient. In those patients with suspected failed reperfusion not undergoing immediate rescue angioplasty $(n=41)$, a policy of repeat angiography and angioplasty for clinical evidence of reinfarction was set.

The incidence of successful rescue angioplasty and failed rescue angioplasty was determined. The requirement for additional revascularisation in those patients receiving rescue angioplasty and in those not initially treated in this way was determined. Finally, the hospital mortality for all patients was calculated. Patients presenting with cardiogenic shock or in shock immediately before cardiac catheterisation were not included in this protocol.

\section{Results}

DETERMINATION OF HIGH RISK WITH EARLY FAILURE TO REPERFUSE

In 1996,220 patients admitted to our coronary care unit with a peak creatine kinase of more than twice the normal upper limit were identified. Notes and ECGs were available for 207 patients $(94 \%)$ and these patients formed the basis of the further analyses (fig 1).

Typical chest pain and ST segment elevation on the admitting ECG were present in 129 patients, and thrombolytic treatment was given to 110 of these $(85 \%)$. Thrombolysis was contraindicated in three patients, one of whom underwent primary percutaneous transluminal coronary angioplasty (PTCA). Thrombolysis was not given in three patients with ST segment elevation because of late presentation, and in one patient because of spontaneous reperfusion. Review of the ECGs on admission (by AGCS) suggested that the remaining 12 patients should probably have received thrombolysis.

In $70(64 \%)$ of the 110 patients with ST segment elevation receiving thrombolysis, the post-thrombolysis ECG showed a reduction of $\geqslant 50 \%$ in the ST segment elevation in the lead with the maximum initial elevation. In 40 patients $(36 \%)$, there was a reduction of $<50 \%$ in this lead on the post-thrombolysis ECG. The mean (SD) time to the post-thrombolysis ECG was 132 (34) minutes (range 80-240 minutes). Of the 40 patients with less than $50 \%$ ST segment resolution, only 14 underwent urgent angiography. The 30 day mortality in the group with persistent ST segment elevation following thrombolysis was $15 \%$, in comparison with $1.4 \%$ in those with $\geqslant 50 \%$ ST segment resolution, confirming the findings of other investigators that persistent ST elevation is a marker of poor prognosis.

POLICY OF ANGIOGRAPHY AND RESCUE ANGIOPLASTY FOR ECG EVIDENCE OF FAILED REPERFUSION

Rescue angioplasty was performed in 156 patients, including 37 in the angiographic substudy. Analysis was performed on the total cohort of 197 patients (fig 2). The mean (SD) time from the onset of major symptoms to thrombolysis was 212 (160) minutes. The mean time from the onset of thrombolysis to coronary angiography was 231 (160) minutes. The mean time from the onset of symptoms to coronary angiography was 465 (363) minutes (fig 3). The time of onset of chest pain was unclear in five patients. Of the 197 patients undergoing coronary angiography for presumed failure of thrombolytic treatment, 178 underwent the procedure within 12 hours of

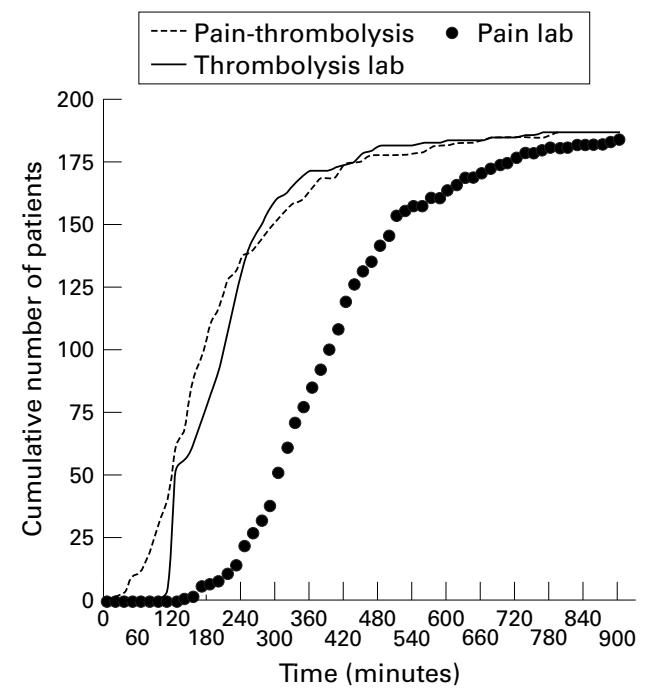

Figure 3 Pain to thrombolysis times, thrombolysis to angiography times, and pain to angiography times for all patients undergoing angiography with or without rescue angioplasty. 
Table 1 Laboratory procedures and clinical outcomes of patients undergoing attempted rescue angioplasty $(n=156)$

\begin{tabular}{ll}
\hline Procedure/outcome & Number (\%) \\
\hline PTCA alone & $68(42.3 \%)$ \\
PTCA + stent(s) & $82(52.6 \%)$ \\
TEC + PTCA & 2 \\
Attempted TEC (failed) & 1 \\
Failure to cross lesion & 3 \\
IABP & $56(36 \%)$ \\
Abciximab & $33(21 \%)$ \\
Successful laboratory procedure & $134(86 \%)$ \\
$\quad$ Deaths & $8(6.0 \%)$ \\
Unsuccessful laboratory procedure & $22(14 \%)$ \\
Deaths & $10(45 \%)$ \\
Total hospital mortality & $11.5 \%$
\end{tabular}

IABP, intra-aortic balloon pump; PTCA, percutaneous transluminal coronary angioplasty; TEC, transluminal extraction catheter.

the onset of symptoms and $19(9.6 \%)$ more than 12 hours after the onset of major symptoms; these underwent coronary angiography because of continuing chest pain.

PATIENTS TREATED WITH RESCUE ANGIOPLASTY Rescue angioplasty was attempted in 156 patients (table 1). Of these, 132 had occlusion of the infarct related vessel at initial contrast injection, 10 had TIMI 1 flow, 13 had TIMI 2 flow, and one had TIMI 3 flow, but the risk of reocclusion without immediate intervention was considered excessive. Coronary artery stents were deployed in 86 patients $(55 \%)$, intra-aortic balloon pumps in $56(36 \%)$, and abciximab in $33(21 \%)$. The target vessel was the left anterior descending coronary artery in 71 , the right coronary artery in 74 , the circumflex artery in 10, and saphenous vein graft to the right coronary artery in one.

TIMI 3 flow was achieved in 124 patients (79\%) and TIMI 2 flow in a further 11, of whom two had TIMI 3 flow before a final high pressure inflation within a coronary stent. Final TIMI flow was less than grade 2 in 21 patients $(13.5 \%)$, including one who underwent emergency coronary artery bypass grafting (CABG). Reinfarction following rescue PTCA occurred in three patients $(1.9 \%)$, including one patient with a successful rescue angioplasty to the left anterior descending coronary artery who then acutely occluded the right coronary artery. Four patients underwent CABG following rescue angioplasty. Of these, two underwent elective predischarge CABG after successful rescue angioplasty procedures. One patient underwent emergency CABG after a partially successful procedure to the right coronary artery which failed to restore normal antegrade flow, and one patient - who had been on the waiting list for elective CABG for multivessel disease-went directly to cardiac theatre following a technically successful rescue angioplasty to the left anterior descending coronary artery.

REINFARCTION/POSTINFARCTION ANGINA IN THE "NO RESCUE" GROUP

In this group, 35 patients had normal antegrade flow at initial angiography and did not undergo immediate rescue angioplasty. Six patients had abnormal flow in the infarct related vessel, but also did not undergo immediate rescue angioplasty, as follows:

- one patient with TIMI 2 flow in the circumflex artery and severe triple vessel disease treated by intra-aortic balloon pump with a view to CABG, but who subsequently died;

- one patient with TIMI 2 flow in the left anterior descending coronary artery and severe triple vessel disease treated by intraaortic balloon pump and CABG;

- one patient with severe triple vessel disease with a persistently occluded left anterior descending coronary artery treated by CABG;

- one patient with TIMI 2 flow in the distal right coronary artery with a distal occlusion;

- one patient with a persistently occluded right coronary artery 12.5 hours into the infarct who was pain free and had evidence of collateral flow to the distal vessel;

- one patient with TIMI 2 flow in the left anterior descending coronary artery who was allergic to aspirin, had a diffusely diseased artery, and was pain free.

For all patients undergoing coronary angiography but not immediate angioplasty, it was decided that angioplasty would be done if there was reinfarction. PTCA for reinfarction was performed in six patients and for postinfarct angina in one patient in this group (table 2). Two more patients had further pain and ECG changes suggestive of reinfarction but did not undergo PTCA. Six patients in this group underwent CABG during the hospital admission for multivessel disease. Thus reinfarction or requirement for revascularisation during the same hospital admission occurred in $37 \%$ of patients with ECG evidence of failed thrombolysis who did not undergo immediate rescue PTCA.

Table 2 Details of patients with no rescue PTCA, successful rescue PTCA, and unsuccessful rescue PTCA

\begin{tabular}{|c|c|c|c|c|}
\hline Total $(n=197)$ & $\begin{array}{l}\text { "No rescue" } \\
\text { group }(n=41)\end{array}$ & $\begin{array}{l}\text { TIMI } 2 / 3 \text { rescue } \\
\text { group }(n=135)\end{array}$ & $\begin{array}{l}\text { TIMI }<2 \text { rescue } \\
\text { group }(n=21)\end{array}$ & $p$ Valuet \\
\hline Age (years) (mean (SD)) & $63.8(10.9)$ & $61.8(10.8)$ & $63.5(9.4)$ & $0.48^{\star}$ \\
\hline Male $(n=137)$ & $26(63 \%)$ & $94(70 \%)$ & $17(81 \%)$ & $0.57^{\star \star}$ \\
\hline Female $(n=60)$ & $15(37 \%)$ & $41(30 \%)$ & $4(19 \%)$ & $0.37^{\star \star}$ \\
\hline Time from onset of symptoms to lab (min) (mean (SD)) & $375(13)$ & $491(421)$ & $470(226)$ & $0.74^{\star}$ \\
\hline Time from onset of lysis to lab (min) (mean (SD)) & $190(70)$ & $238(168)$ & $264(217)$ & $0.63^{\star}$ \\
\hline "Out of hours" ( $5 \mathrm{pm}$ to $9 \mathrm{am})$ & $22(54 \%)$ & $72(53 \%)$ & $11(52 \%)$ & $0.96^{\star \star}$ \\
\hline Patients transferred from neighbouring CCUs $(n=91)$ & $20(46 \%)$ & $76(57 \%)$ & $15(68 \%)$ & $0.45^{\star \star}$ \\
\hline PTCA for reinfarction & $8(19.5 \%)$ & $3(2.2)$ & $0(0 \%)$ & $0.49^{\star \star}$ \\
\hline In-hospital CABG & $6(14.6 \%)$ & $2(1.5 \%)$ & $2(9.5 \%)$ & $0.03^{\star \star}$ \\
\hline PTCA for postinfarct angina & $1(2.4 \%)$ & $0(0 \%)$ & $0(0 \%)$ & NA \\
\hline Hospital mortality $(\mathrm{n}=21 ; 10.7 \%)$ & $3(7.3 \%)$ & $8(6.0 \%)$ & $10(45 \%)$ & $<0.001^{\star \star}$ \\
\hline
\end{tabular}

†TIMI $2 / 3$ rescue PTCA $v$ TIMI $<2$ rescue PTCA.

${ }^{\star}$ Student $t$ test; ${ }^{\star \star} \chi^{2}$ test.

CABG, coronary artery bypass grafting; CCU, coronary care unit; PTCA, percutaneous transluminal coronary angioplasty; TIMI, thrombolysis in myocardial infarction trial. 
Table 3 Initial and final TIMI flow rates for patients undergoing rescue PTCA $(n=156)$

\begin{tabular}{|c|c|c|c|c|}
\hline \multirow{2}{*}{$\begin{array}{l}\text { Initial TIMI flow } \\
(X)\end{array}$} & \multicolumn{4}{|c|}{ Final TIMI flow (Y) } \\
\hline & TIMI 0 & TIMI 1 & TIMI 2 & TIMI 3 \\
\hline TIMI $0(n=125)$ & $\mathrm{n}=8(6.4 \%)^{\star}$ & $\mathrm{n}=7(5.6 \%)$ & $\mathrm{n}=9(7.2 \%)$ & $\mathrm{n}=101(80.8 \%)$ \\
\hline TIMI 1 (n=17) & $\mathrm{n}=1(5.9 \%)$ & $\mathrm{n}=4(23.5 \%)$ & $\mathrm{n}=1(5.9 \%)$ & $\mathrm{n}=11(64.7 \%)$ \\
\hline TIMI $2(n=13)$ & $\mathrm{n}=0(0 \%)$ & $\mathrm{n}=1(7.7 \%)$ & $\mathrm{n}=1(7.7 \%)$ & $\mathrm{n}=11(84.6 \%)$ \\
\hline TIMI $3(n=1)$ & $\mathrm{n}=0(0 \%)$ & $\mathrm{n}=0(0 \%)$ & $\mathrm{n}=0(0 \%)$ & $\mathrm{n}=1(100 \%)$ \\
\hline
\end{tabular}

*Values in brackets are percentages of patients with initial flow rate $\mathrm{X}$ reaching final flow rate $\mathrm{Y}$.

INITIAL AND FINAL TIMI FLOW RATES

The TIMI flow rates at initial angiography and following successful or failed rescue angioplasty for patients in the rescue angioplasty group are shown in table 3.

HOSPITAL MORTALITY

There were 21 in-hospital deaths among the whole group (mortality 10.7\%); there were 18 hospital deaths in the rescue angioplasty group (mortality $11.5 \%$ ). The hospital mortality for patients leaving the catheter laboratory with TIMI 3 flow was $6.5 \%$ (eight patients) and for patients with TIMI 2 or TIMI 3 flow $5.9 \%$ (the same eight patients). Of these patients, one sustained a cardiac arrest associated with electromechanical dissociation and was found at necropsy to have sustained cardiac rupture, one patient died from bronchopneumonia, one patient died after a laparotomy for bowel infarction, and the remaining five developed cardiogenic shock.

For patients leaving the catheter laboratory with < TIMI 2 flow, the hospital mortality was $48 \%$ (10 patients). A large thrombus burden was seen in many of the patients in whom rescue angioplasty was unsuccessful. These patients include one who died from intractable ventricular fibrillation despite a technically successful emergency coronary artery bypass operation.

Mortality appeared to be reduced among patients undergoing rescue angioplasty within eight hours of the onset of major symptoms $(10.5 \%)$ in comparison with those undergoing the procedure more than eight hours after the onset of major symptoms $(13.7 \%)$, but this difference was not significant. Three deaths occurred in the "no rescue" group. There were no significant complications associated with the use of intra-aortic balloon pumps (no requirement for vascular repair, no irreversible ischaemia). The mortality in patients undergoing rescue angioplasty but not receiving one or more coronary artery stents was $14.3 \%$, compared with $8.5 \%$ in the group receiving one or more stents $(\mathrm{p}=0.29)$.

\section{Discussion}

The diagnosis of failed thrombolysis is difficult and the management unclear. Although complex algorithms based upon ECG analysis or measurement of cardiac enzymes have been described, it is doubtful whether such methods are applicable in the setting of a district general hospital coronary care unit. Our method of identifying patients with probable failed thrombolysis has limitations, but does identify a high risk group. The method might be improved by considering the presence or absence of chest pain, and/or the presence or absence of any reperfusion arrhythmia following thrombolytic treatment, which we have discussed previously. ${ }^{12}$ We accept that, in the absence of regional or national guidelines on the diagnosis and management of failed reperfusion, it is often unclear how the surrounding coronary care units have made a diagnosis of failed reperfusion and on what criteria some of these patients are then referred to the regional centre. Some units do not look for evidence of failed reperfusion at all. ${ }^{10}$ In general, it is highly likely that patients referred for consideration of failed reperfusion are those perceived be at higher risk-for example, those with anterior rather than inferior myocardial infarction.

Once failed reperfusion is identified, the further management options include coronary artery bypass surgery or the use of repeat thrombolysis. We know of no studies to support the former approach. Only one small trial has tested the latter approach, showing that benefit was confined to those patients who failed to reach a lytic state following initial streptokinase. ${ }^{13}$ Reports from other nonrandomised studies have indicated some possible benefit from a strategy of repeat thrombolysis, but these results should be interpreted with caution, given the nature of the studies. ${ }^{14}$ In addition, there is evidence that the presence of a lytic state is not always associated with a patent infarct related vessel. ${ }^{15}$ Hence the repeated administration of thrombolytic agents in order to achieve a lytic state will not necessarily produce a patent vessel and is likely to increase the risk of haemorrhagic complications.

Repeat thrombolysis could be augmented by intra-aortic balloon counterpulsation, a treatment that may improve late patency of the occluded infarct related vessel and has been shown to be beneficial in cardiogenic shock. ${ }^{16}{ }^{17}$ Thrombolytic treatment with glycoprotein IIb/ IIIa inhibitors could also be given. The TIMI-14 trial showed TIMI 3 flow rate at 60 minutes in only $43 \%$ of patients receiving standard doses of alteplase for acute myocardial infarction, but in $72 \%$ of those receiving half the standard dose of alteplase plus abciximab. There was no difference in the incidence of major haemorrhage. However, we know of no study where glycoprotein IIb/IIIa inhibitors have been given solely for failure of initial thrombolytic treatment.

Another therapeutic option for failed thrombolysis is rescue angioplasty. Following an analysis of 560 patients undergoing rescue angioplasty (mortality $10.6 \%$, reocclusion rate $18 \%$ ), ${ }^{18}$ Ellis and colleagues performed a dedicated trial of rescue angioplasty versus conservative treatment in patients with their first anterior myocardial infarction. ${ }^{9}$ This showed a reduced incidence of death or severe heart failure at 30 days in the angioplasty group in comparison with the conservative group $(6.4 \% \vee 16.6 \%$, $\mathrm{p}=0.05)$. The angioplasty group had significant preservation of exercise (though not resting) ejection fractions, as measured by multiple gated equilibrium radionuclide techniques (mean (SD): 43 (15)\% v 38 (13)\%; p = 0.04). A very small trial by Belenkie and colleagues, 
involving just 28 patients, failed to show any benefit from a strategy of rescue angioplasty. ${ }^{19}$ Subsequent meta-analysis of these two trials also failed to show a mortality benefit. ${ }^{20}$

The RESCUE (randomised evaluation of salvage angioplasty with combined utilisation of endpoints) trial might have underestimated the benefit of rescue angioplasty for various reasons:

- Patients were randomised eight hours after the onset of chest pain, so benefit from revascularisation is likely to be smaller than in patients presenting early and who are offered rescue angioplasty very soon after thrombolytic treatment is deemed to have failed.

- The trial failed to make use of intra-aortic balloon counterpulsation in the angioplasty arm, a treatment which has been shown to be beneficial during rescue angioplasty. ${ }^{21} 22$

- High risk patients - such as those with a previous myocardial infarct or left main stem disease-who might have the most to gain from revascularisation were excluded.

- The trial was performed without modern glycoprotein IIb/IIIa inhibitors, such as abciximab. These agents have been shown to be beneficial in high risk angioplasty, ${ }^{23}$ and recently in the setting of rescue angioplasty for failed thrombolysis. ${ }^{24}$

- Finally it seems likely that in the modern stent era, arterial patency can be maintained after initial intervention, which itself results in an open vessel in over $85 \%$ of cases.

This latter is supported by more recent data from patients undergoing rescue angioplasty in the angiographic substudy of GUSTO- $1 .{ }^{25}$ Rescue angioplasty resulted in superior left ventricular function and 30 day mortality rates in comparison with patients treated conservatively following the angiographic demonstration of a persistently occluded infarct related vessel after thrombolytic treatment. In addition, this study firmly contradicts the findings of the TIMI-IIA trial ${ }^{26}$ and the trial by O'Neill and colleagues, ${ }^{27}$ which had shown unacceptably high rates of non-coronary complications following angioplasty in the context of previous administration of thrombolytic treatment.

Small retrospective analyses have suggested that stenting in rescue angioplasty is feasible, safe, and associated with better angiographic results and possibly improved outcome. ${ }^{28} 29$ Our experience also suggests a trend towards improved outcome in the stented group.

In this analysis we have excluded patients who had clear evidence of cardiogenic shock at initial presentation and those with shock at the time of coronary angiography. In our view, these exclusions are justifiable. It is our belief that the optimal management of patients with cardiogenic shock is to attempt percutaneous coronary intervention, preferably without previous thrombolytic treatment, and we believe there is an increasing amount of data to support this approach. ${ }^{30}$ We also consider for urgent angioplasty those patients who have received thrombolytic treatment but then develop cardiogenic shock, even if the ECG suggests reperfusion. Patients with ECG evidence of failed reperfusion but without cardio- genic shock present a more difficult management decision, as mortality in such patients is also high but there is a less clear benefit from attempted percutaneous revascularisation. In the absence of shock and persistent ST segment elevation, the use of rescue angioplasty can be gauged against the use of repeat thrombolytic treatment, because these patients could be considered for such an approach, whereas patients with shock should not. Current trials are assessing these two options.

The case for rescue angioplasty remains unproven. However, our experience to date has provided some insights.

First, even with a change in our coronary care unit protocol, early investigation for evidence of failed thrombolysis took some time to become established practice. Referral for consideration of rescue angioplasty by the duty physician to the duty cardiologist was initially infrequent, although the referral rate increased with time.

Second, given the wide range of times between the onset of thrombolytic treatment and initiation of coronary angiography (range 75-1220 minutes, mean 231 minutes), it seems likely that those referred for consideration of rescue angioplasty have been subjected to a selection process which depends on such diverse factors as the time of day, the admitting consultant, and the proximity of the time of the post-thrombolysis ECG to the next coronary care unit ward round.

Third, the evidence collected to date supports the view that a policy aimed at restoring arterial flow should be initiated as soon as thrombolytic treatment is deemed to have failed. An early ECG is just as good at identifying patients at high risk following unsuccessful thrombolytic treatment as a later one. ${ }^{7}$ While the mean time from onset of symptoms to arrival in the cardiac catheterisation laboratory was 470 minutes, it is noteworthy that the mean time from the administration of thrombolytic treatment to arrival in the laboratory was almost four hours. In other words, the time between the onset of thrombolytic treatment and angiography was approximately half the total time between the onset of major symptoms and arrival in the cardiac catheterisation laboratory. There is scope for reducing this time delay if ECG evidence of failed thrombolysis is sought early and acted upon promptly. The mortality in the patients undergoing rescue angioplasty more than eight hours after the onset of symptoms (13.7\%) is comparable with that in the conservatively treated lytic failure group. Hence the additional costs and risks of attempted rescue angioplasty in this group may not be worth the risk.

Fourth, we have shown that a policy of emergency coronary angiography for failed reperfusion, proceeding to rescue angioplasty when indicated, is associated with a lower mortality than that expected for patients with persistent ST segment elevation following thrombolytic treatment $(10.7 \%$ v 15-20\%).

Finally, rescue angioplasty itself can be performed with a high degree of technical success. Almost $80 \%$ of patients in the angioplasty 
group achieved TIMI 3 flow by the end of the procedure and a further 11 patients had TIMI 2 flow. The British Cardiovascular Intervention Society's definition of a successful angioplasty procedure in elective cases is a $<50 \%$ residual stenosis, no death, no myocardial infarction, and no emergency CABG. The definition of a successful procedure for infarct angioplasty is less clear, but should probably include normal antegrade flow at the end of the procedure, even though there is evidence to show that the presence of TIMI 3 flow does not necessarily produce normal cellular perfusion. ${ }^{31}$ The mortality among patients leaving the catheter laboratory with TIMI 3 flow was $6.5 \%$ considerably lower than the expected mortality with conservative treatment. In our view, the 11 patients with TIMI 2 flow at the end of the procedure also received benefit from intervention, as nine patients had started with a totally occluded vessel, all left the catheter laboratory in a haemodynamically stable condition, and all survived to discharge without clinical or ECG evidence of reinfarction, suggesting that the infarct related vessel remained patent.

Our expectation from this analysis is that a policy of early angiography following detection of failed reperfusion with a view to performing rescue angioplasty-in conjunction with coronary stenting, antiplatelet treatment, and intra-aortic balloon pumping when appropriate-will save lives, in comparison with a strategy of conservative treatment. However, the expected high mortality in those patients with a persistently occluded infarct related vessel at angiography might also be reduced by more simple interventions, such as the administration of glycoprotein IIb/IIIa inhibitors or the use of intra-aortic balloon pumping, without a percutaneous attempt to open the infarct related vessel. The mortality from a failed rescue angioplasty procedure remains high, and our results are in keeping with those of other investigators. ${ }^{32}$ While acknowledging this weakness of rescue angioplasty, it is to be hoped that the number of failed procedures will be reduced by regular observation for signs of failed reperfusion, by prompt diagnosis and patient transfer, and by the new adjunctive treatments available to reduce the risk of abrupt vessel closure and subacute stent thrombosis. We believe that the overall strategy described here is also advantageous for those patients who are initially slow to reperfuse with thrombolytic treatment, but who reperfuse within the next three or four hours and are found to have normal flow at angiography. We have shown that such patients have a high requirement for revascularisation during the same hospital admission.

In our view, further prospective randomised trials of rescue angioplasty are required, using all the modern adjunctive treatments available. We believe that the use of intracoronary stents, intra-aortic balloon counterpulsation, and the new antiplatelet agents now available will lead to a greater degree of technical success in the cardiac catheter laboratory in patients in whom thrombolytic treatment has been unsuccessful. We would expect that rapid transfer to an inter- vention centre following an early diagnosis of failed thrombolysis will further enhance the ability to recanalise persistently occluded vessels and preserve left ventricular function. Until the results of such trials are available, we would emphasise the importance of liaison between district general hospitals and regional cardiothoracic centres, with discussion of policy for the further management of patients with persistent ST segment elevation following thrombolysis.

1 The GUSTO Angiographic Investigators. The effects of tissue plasminogen activator, streptokinase, or both on coronary artery patency, ventricular function and survival after 22 .

2 The TIMI Study Group. The thrombolysis in myocardial infarction (TIMI) trial: phase 1 findings. $N$ Engl $\mathcal{F} \mathrm{Med}$ 1985;312:932.

3 Simes RJ, Topol EJ, Holmes DR, et al, for the GUSTO-1 Investigators. Link between the angiographic substudy and mortality outcomes in a large randomized trial of myocardial reperfusion. Circulation 1995;91:1923-8.

4 Karagounis L, Sorensen SG, Menlove RL, et al. Does thrombolysis in myocardial infarction (TIMI) perfusion grade 2 represent a mostly patent artery or a mostly occluded artery? Enzymatic and electrocardiographic evidence from the TEAM-2 study. Second multicenter thrombolysis trial of eminase in acute myocardial infarction. F Am Coll Cardiol 1992;19:1-10.

5 Anderson JL, Karagounis LA, Becker LC, et al, and the TEAM-3 Investigators. TIMI perfusion grade 3 but not grade 2 results in improved outcome after thrombolysis for myocardial infarction: ventriculographic, enzymatic and electrocardiographic evidence from the TEAM-3 study. Circulation 1993;87:1829-39.

6 Anderson JL, Karagounis LA, Califf RM. Metaanalysis of five reported studies on the relation of early coronary patency grades with mortality and outcomes after acute myocardial infarction. Am $\mathcal{f}$ Cardiol 1996;78:1-8.

7 Purcell IF, Newall N, Farrer M. Change in ST segment elevation 60 minutes after thrombolytic initiation predicts clinical outcome as accurately as later changes. Heart 1997; 78:465-71

8 Schroder R, Wegscheider K, Schroder K, et al. Extent of early ST segment elevation resolution: a strong predictor of outcomes in patients with acute myocardial infarction and a sensitive measure to compare thrombolytic regimens. A substudy of the international joint efficacy comparison of thrombolytics (INJECT) trial. F Am Coll Cardiol 1995;27: 1657-64.

9 Ellis SG, da Silva ER, Heyndrickx G, et al. Randomized comparison of rescue angioplasty with conservative management of patients with early failure of thrombolysis for acute anterior myocardial infarction. Circulation 1994;90: 2280-4.

10 Prendergast BD, Shandall A, Buchalter MB. What do we do when thrombolysis fails? A United Kingdom survey. Int 7 Cardiol 1997;61:39-42.

11 Yee K-M, Pringle SD. Failure of reperfusion following thrombolysis in acute myocardial infarction: a survey of curren views and clinical practice. Br f Cardiol 1998;5:35-45.

12 Sutton AGC, Campbell PG, Price DJA, et al. Failure of thrombolysis by streptokinase: detection with a simple electrocardiographic method. Heart 2000:84:149-56.

13 Mounsey JP, Skinner JS, Hawkins T, et al. Rescue thrombolysis: alteplase as adjuvant treatment after streptokinase in acute myocardial infarction. $\mathrm{Br}$ Heart $f$ 1995;74:348-53.

14 Drenth JPH, Uppelschoten A, Hooghoudt TEH, et al. Rescue thrombolysis may work even though primary thrombolysis has failed. BMF 1998;317:147.

15 el Gaylani N, Davies S, Tovey J, et al. Systemic lytic state is not a predictor of coronary reperfusion in acute myocardial infarction. Int $\mathcal{F}$ Cardiol 1996;57:45-50.

16 Kono T, Morita H, Nishina T, et al. Aortic counterpulsation may improve late patency of the occluded coronary artery in patients with early failure of thrombolytic therapy. $7 \mathrm{Am}$ in patients with early failure of

17 Kovak PJ, Rasak MA, Bates ER, et al. Thrombolysis plus aortic counterpulsation: Improved survival in patients who present to community hospitals with cardiogenic shock. $\mathcal{F}$ Am Coll Cardiol 1997;29:1454-8.

18 Ellis SG, Van de Werf F, Ribeiro-daSilva E, et al. Present status of rescue coronary angioplasty: current polarization of opinion and randomized trials. F Am Coll Cardiol 1992;19:681-6.

19 Belenkie I, Traboulsi M, Hall CA, et al. Rescue angioplasty during myocardial infarction has a beneficial effect on mortality: a tenable hypothesis. Can 7 Cardiol 1992;8:35762.

20 Michels KB, Yusuf S. Does PTCA in acute myocardial infarction affect mortality and reinfarction rates? A quantitaarction affect mortality and reinfarction rates? A quantita-
tive overview (meta-analysis) of the randomized clinical

21 Ishihara $M$, Sato $\mathrm{H}$, Tateishi $\mathrm{H}$, et al. Intraaortic balloon pumping as adjunctive therapy to rescue coronary angioplasty after failed thrombolysis in anterior wall acute myocardial infarction. Am $\mathcal{F}$ Cardiol 1995;76:73-5. 
22 Ohman EM, George BS, White CJ, et al, and the Randomized IABP Study Group. Use of aortic counterpul-
sation to improve sustained coronary artery patency during sation to improve sustained coronary artery patency during acute myocardial infarction:

23 The EPILOG Investigators. Platelet glycoprotein IIb/IIIa receptor blockade and low-dose heparin during percutaneous coronary revascularization. $N$ Engl $\mathcal{F}$ Med 1997;336 1689-96.

24 Miller JM, Smalling R, Ohman EM, et al. Effectiveness of early coronary angioplasty and abciximab for failed thrombolysis (reteplase or alteplase) during acute myocardial infarction (results from the GUSTO-III trial). Global use of strategies to open occluded coronary arteries. Am 7 Cardiol 1999;84:779-84

25 Ross AM, Lundergan CF, Rohrbeck SC, et al, for the GUSTO-1 Angiographic Investigators. Rescue angioplasty after failed thrombolysis: technical and clinical outcomes in a large thrombolysis trial. F Am Coll Cardiol 1998;31:151117.

26 The TIMI Study Group. Comparison of invasive and conservative strategies after treatment with intravenous tisconservative strategies after treatment with intravenous tis-
sue plasminogen activator in acute myocardial infarction. $N$ sue plasminogen activator in acut
27 O'Neill Ww, Weintraub R, Grines CL, et al. A prospective, placebo-controlled, randomized trial of intravenous streptokinase and angioplasty versus lone angioplasty therapy of acute myocardial infarction. Circulation 1992;86:1710-17.

28 Cafri C, Denktas AE, Crystal E, et al. Contribution of stenting to the results of rescue PTCA. Cathet Cardiovasc Intervent 1999;47:411-14.

29 Moreno R, Garcia E, Abeytua M, et al. Coronary stenting during rescue angioplasty after failed thrombolysis. Cathet Cardiovasc Intervent $1999 ; 47: 1-5$.

30 Hochman JS, Sleeper LA, Webb JG, et al. Early revascularization in acute myocardial infarction complicated by cardiogenic shock. SHOCK Investigators (Should we emergently revascularize occluded coronaries for cardiogenic shock). $N$ Engl f Med 1999;341:625-34.

31 Ito $\mathrm{H}$, Tomooka $\mathrm{T}$, Sakai $\mathrm{N}$, et al. Lack of myocardial perfusion immediately after successful thrombolysis: a predictor of poor recovery of left ventricular function in anterior myocardial infarction. Circulation 1992:85:1699-705.

2 Gor m, HJ, Klaus AP, et al. Rescue

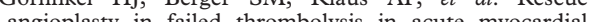
anioplasty in failed thrombolysis in infarction: a community hospital experience. I Invas Cardiol 1997;9:83-7.

\section{IMAGES IN CARDIOLOGY}

\section{Diagnostic value of a subtherapeutic adenosine dose}

Over the last 10 years adenosine has become the initial drug administered for narrow complex tachycardia, or for broad complex tachycardia where a diagnosis other than ventricular tachycardia is suspected. The response to adenosine depends on the tachycardia mechanism. Atrial arrhythmias usually do not terminate, but unmasking the atrial rhythm by temporarily increasing atrioventricular
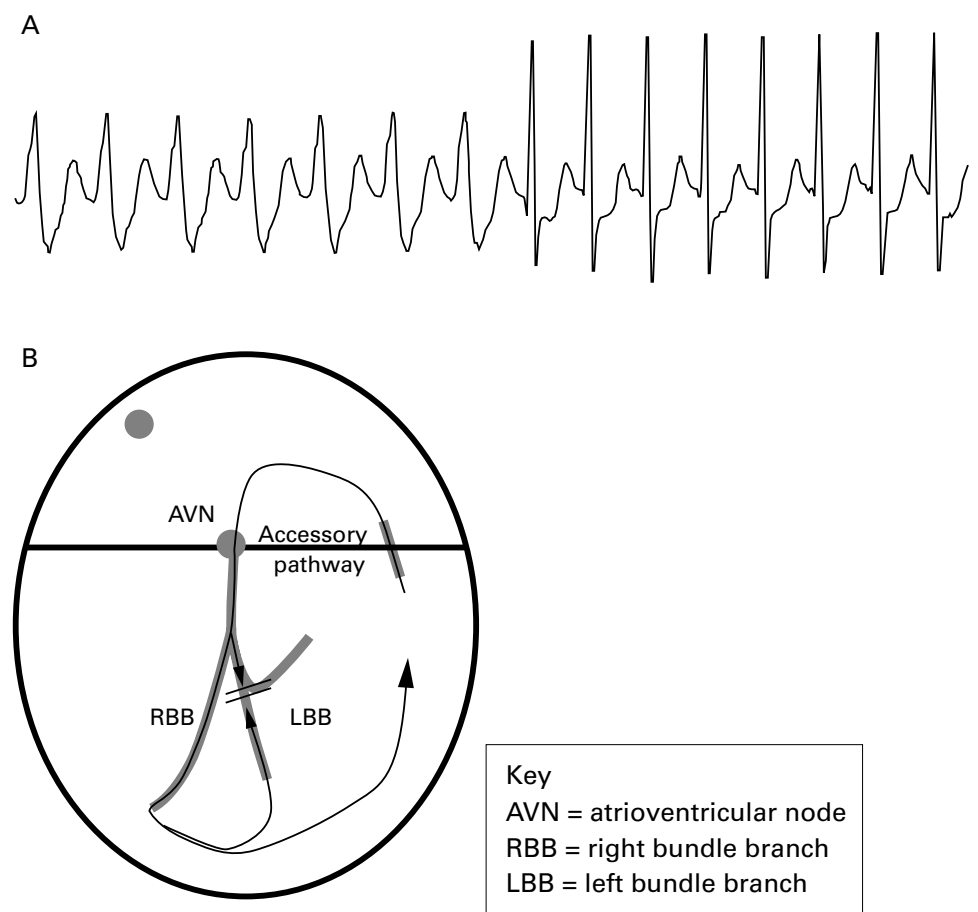

block (AV) is diagnostically helpful. Arrhythmias utilising the AV node (AV nodal reentrant tachycardia and AV reciprocating tachycardia) terminate if AV block is achieved. Finally, ventricular tachycardia usually shows no response, although occasional ventricular (and atrial) tachycardias are adenosine sensitive. Occasionally a subtherapeutic dose of adenosine may provide very precise diagnostic information.

A 52 year old man attended casualty with his first prolonged bout of palpitations. The initial ECG showed a left bundle branch block (LBBB) morphology broad complex tachycardia with a rate of 170 beats per minute (bpm). Intravenous adenosine $3 \mathrm{mg}$ changed this into a narrow complex tachycardia at $210 \mathrm{bpm}$ (A, top). A further $6 \mathrm{mg}$ bolus of adenosine restored sinus rhythm. The patient's resting ECG was within normal limits with no evidence of pre-excitation.

The diagnosis is orthodromic AV reciprocating tachycardia utilising a left sided accessory pathway. During the LBBB tachycardia, the tachycardia circuit conducted anterogradely over the right bundle, and retrograde invasion of the left bundle maintained the LBBB (B, bottom). Slight slowing of AV nodal conduction by the adenosine allowed recovery of excitability, and since the impulse could now reach the accessory pathway via the left bundle, the circuit became shorter and the tachycardia rate faster.

JOHAN E P WAKTARE JOHN P LYONS 